ISBN 978-981-11-3671-9

(WCSE 2017)

Beijing, 25-27 June, 2017, pp. 558-562

doi: $10.18178 /$ wcse.2017.06.096

\title{
Coolite and LINQ Applied in the Development of a Web-based Operations Management System for the Crafting Industry: Case JPDAL
}

\author{
Pablo Alejandro Quezada - Sarmiento ${ }^{1,2+}$, Laura Magali Chamba- Rueda ${ }^{1}$, Mariuxi Claribel Pardo- \\ Cueva $^{1}$, Liliana Enciso ${ }^{1}$ \\ ${ }^{1}$ Universidad Tecnica Particular de Loja, ${ }^{2}$ Universidad Internacional del Ecuador \\ Department of Electronics and Computer Science, Escuela de Informática y Multimedia, Departamento \\ Ciencias Administrativas, Grupo Innovación Tecnológica Educativa (GITE), Grupo de Investigación: \\ Calidad, Innovación y eficiencia Organizacional -CIEO
}

\begin{abstract}
To develop a Web-based Operations Management System, through technologies such as Coolite and LINQ, to systematically manage processes in the Crafting Industry in the Loja city (JPDAL). As part of the software development methodology, XP (Extreme Programming) was used across all its phases. This allowed to clearly determine the necessary requirements for the development of an accessible, scalable, and secure application (Web-based Operations Management System) that could fulfil all the functionalities raised by the stakeholders. The theoretical-scientific framework that supports the research, as well as the elements that allowed an appropriate development of the application, were established.

To improve processes within the Crafting Industry, a Web-based Operations Management System, based on technologies such as Coolite and LINQ, was developed. Inherently, and more importantly, the application of these technologies allowed for a more accessible and adaptable user interface.
\end{abstract}

Keywords: Coolite, Crafting Industry, Linq, XP, Web.

\section{Introduction}

The concept of craftsmanship is fused with that of "popular art", understood as that group of manual and productive activities carried out by an individual, a group, or a family, and traditionally transmitted from parents to children. This ancestral knowledge, thoroughly connected to the raw material, is often manifested in hundreds of objects that showcase the value and high-quality of the Ecuadorian Crafting Industry while reflecting, in an extraordinary way, the cultural diversity of each one of its provinces [1].

Furthermore, through out history artisans have played a leading role since, thanks to them, the identity of Ecuador has been globally recognized. No doubts why in most of its recent national endeavours, particularly in the struggle for social and economic rights, the artisans have been present [2]. Accordingly, JPDAL the principles that guide this noble economic, cultural and fundamental human activity, proposes actions with and from the people; this includes new approaches to the social and solidarity economy while anchoring ethics in their actions [2]. This document outlines the automation of administrative processes of the Crafting Industry through a Web application (simulating a basic Operations Management System) developed in Visual Studio Team System 2017, using SQL Server 2016 as a database, and Sharp C as the main programming language. As an engineering contribution, AJAX and Coolite were applied as key components for a more dynamic user interface [9]. The application of LINQ for mapping control and interaction with the database was considered necessary as well.

\section{Background}

\footnotetext{
+ Corresponding author. Tel.: + 593939806396.

E-mail address: paquezada@utpl.edu.ec,paquezadasa@internacional.edu.ec.
} 
ASP.NET. - Web application framework developed and commercialized by Microsoft, and used by programmers to build dynamic websites, web applications and XML web services. It appeared in January 2002, within the 1.0 version of the .NET Framework, as the successor of the Active Server Pages (ASP) technology. Moreover, ASP.NET is built on top of the Common Language Runtime, allowing programmers to write ASP.NET code using any other language supported by the .NET Framework [3].

Coolite. - Component to use along Visual Studio or Visual Web Developer for running Ext JS scripts. Designed for easiness, a user can simply download it and add its reference to the DLL for later loading of tools [4].

Language Integrated Query (LINQ). - LINQ is a Microsoft project that adds native queries similar to those of SQL and the .NET Framework. It can also work for Visual Base and C\#. The latest LINQ version released by Microsoft includes these libraries and compilers for C\# 3.0 and Visual Basic 9.6 [5].

Firebug. - Extension for Firefox, created and designed for developers and web programmers. It is also a package of utilities that can be useful for analysis (checking load speed, DOM structure), editing, monitoring, and instantly (inline) debugging source code, CSS, HTML, and JavaScript of a Web page [6].

Master Page. - Page that contains tags, controls, code, or any combination of these elements, that must be shared through multiple pages inside the main site [7] [13]. The Operations Management System (Web application) consists of 3 Master Pages: one for the public environment and two for the private [9]. The Master Page of the public environment will be the common framework for freely accessible data for all users. Figure 1 shows the Public Environment Master Page developed for the Web application. Likewise, 2 Master Pages were created for the private environment, one for the Operations, and another for the administration of the site. Figure 2 shows the operations Master Page in use. For the administration of the site (Web application), the master page show in Figure 3 was used.

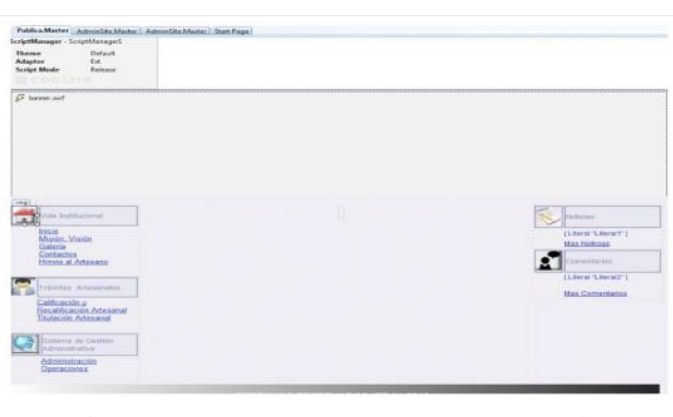

Fig. 1: JPDAL Master Page [9]

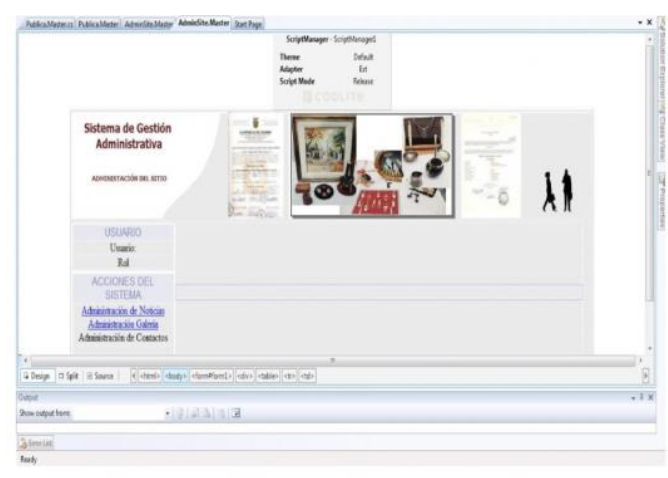

Fig. 2: Private Environment Master Page [9]

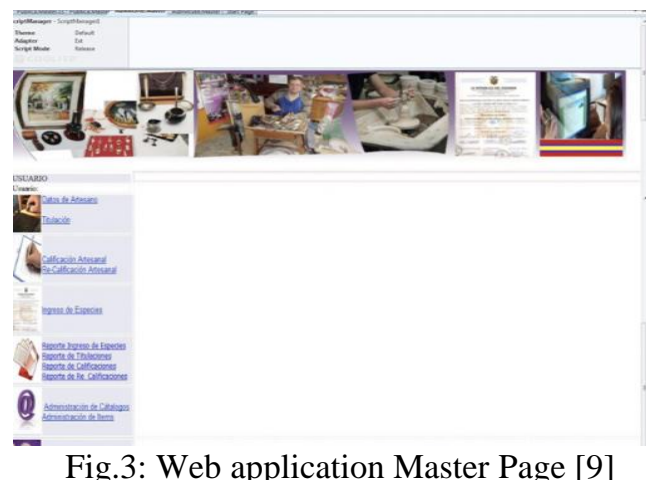

Web Form.- This is a webpage built under the .NET platform, specifically with ASP.NET, and it allows the user to enter the data that will be sent to the web server for later processing. Web forms are similar to paper forms in the sense that Internet users can fill out these forms by using check boxes, radio buttons, and text fields [10].

Web Control.- This is a generic class inherited by all the web controls that are used to design web pages (Web Forms). This term is often used to generalize all visual controls of a webpage built under the .NET platform, mainly with ASP.NET [11]. 
Development Methodology Used .-For the development of the Web application, the guidelines marked by the XP methodology (Extreme Programming) were put in practice. Extreme Programming assumes that planning will never be perfect and that it will vary depending on how the business needs change. Therefore, the real value lies in how quickly a team can obtain an initial plan, and have sufficient feedback mechanisms to know precisely where they are in any given circumstance. Logically, planning is iterative, which means that at the beginning of each iteration, a business representative decides what specific features will be implemented. The purpose of using the XP methodology was to generate versions of the application that could truly provide additional value from the business perspective. These versions are called releases [12].

History is the unit of functionality in an XP project, and it corresponds to the minimum possible functionality that has a value from the business perspective. During each iteration, several 'histories' are closed, which causes that all iterations add tangible value to the customer [12].

In terms of the actual implementation, during the survey and the analysis of requirements phase, it was possible to determine 14 users 'histories' [9]. The involvement of a representative of the client, in this case Lic. Narcisa Sarmiento Ochoa -Administrative Assistant of the JPDAL who was fundamental in all this planning and amid deciding which are the most valuable 'histories'. The client was also responsible for defining the acceptance tests, but not necessarily for their implementation. After completing the development phase, the respective tests to check the pre-established functionalities of the Web application were performed [9]. XP includes, as one of its standard practices, programming in pairs. Nobody programs alone, there are always two people in front of the computer [12]. Another basic practice of Extreme Programming is to use designs as simple as possible. The principle is "to use the simplest design that makes everything work". This suppresses the hype for designing extra features because, in practice, experience indicates that needs that will become real can rarely be anticipated. To achieve a flawless and modifiable source code, it was imperative to implement a consistent coding standard as well "[19], [20] [22].

\section{Results and Disscusion}

Application design .-Once the operative and technical requirements are established and the client needs are also clear, the next step is to proceed with the software solution design. To meet the objectives of this project, different classes, methods and new development tools were considered [9], [14], [18].

The Web application had two main environments as design enablers, one of them public and the other private. The public environment is currently freely accessible and it includes information related to the institution. This through pages such as: 'Who we are', 'Mission and Vision', 'Training information', 'Paperwork requirements', 'Gallery', and 'Comments and information of interest for the Crafting Industry' [9]. In the public environment, users do not only have access to this information but also they enjoy a dynamic and user-friendly graphical interface since Coolite is in use [9].Strictly for management purposes, and as the engine of the database, Microsoft SQL Server 2015 is used. For control and continuos interaction with the database, LINQ is the other technology in place.

On the other side, the private environment deals with the control of the Web application and it handles the administrative processes of the institution and their validation. The Web application can be also structured out of 5 main projects: JPDAL.AccesoDatos, JPDAL.BackEnd, JPDAL.SYS.AccesoDatos, JPDAL.WEB, and RecursosWEB. For all of them, different classes, methods procedures, and data access were implemented so that the application's performance remains reliable.

For this private environment, only pre-defined / authorized personal has been granted (logging module and credentials assigned by a system administrator).

An authorized user can manage the news and comments module while having control of the administrative processes of the institution.

Design and Solution Architecture.- Highest level of design for a system's structure [13], [17], [21] generally combining a set of patterns and coherent abstractions that provide the necessary framework to guide software's development for a given information system. In the development of the Web application, a component-oriented architecture was considered since the type of activities and characteristics of the institution so required. This Web application is comprised of a solution called JPDAL; which at the same 
time consists of the ASP.NET Web Application, a class library, and two databases. One of these databases is BDDInformativo and it stores information regarding press releases, news, and comments on and of the portal. The other, JPDAL_DB, stores information regarding the procedures and administrative processes of the institution [9].

The JPDAL solution is comprised of 5 (ASP.NET Web application and class-library-type) projects. This applies for their respective data accesses as well. Each of these software solution projects is detailed below.

JPDAL.AccesoDatos.- This is a class-library-type project where the application's data accesses will be created both in first and second phase.

JPDAL.BackEnd.- This is another class-library-type project formed by classes and methods that relate to the security, the configurations, and the database connection chains of the project.

JPDAL.SYS.AccesoDatos.- This is a class-library-type project where different classes, methods referring to the administration of the site, and its processes are all included.

JPDAL.WEB.- This is an ASP.NET Web application that contains different asp.cx pages, master pages for both public and private environments, as well as the software's administration and operations.

RecursosWEB.- This is another ASP.NET Web application where certain Web resources and their configuration can be found [9]. For this project two databases were built:

BDDInformativo. - This database stores press releases, news, and comments on and of the portal.

JPDAL_DB. - This database stores the procedures and administrative processes of the institution.

Reports. - Cristal Reports is a business intelligence application used to design and generate reports from a wide range of data sources (databases) [8]. Several applications, such as Microsoft Visual Studio, include an OEM version of Crystal Reports as a general-purpose reporting tool [16] ,[20].

\section{Conclusions}

- Software development and programming are undisputed key stones of the information technology industry. Thus, professionals in this area must be abreast of technological advances and new development tools to effectively serve society.

- With the development of this Web application, administrative and information processes of JPDAL were improved; consequently, the quality of services of the crafting industry in the province increased as well.

\section{Acknowledgment}

The authors express their most sincere gratitude to the Research and Academic Vice-chancellors of Universidad Técnica Particular de Loja PhD. Juan Pablo Suarez Chacón and PhD. Santiago Acosta Aide, for their continuous support towards the diffusion of research findings.

\section{References}

[1] Available at: http://s3.amazonaws.com/lcp/ecuador-pluricultural/myes/ LA-ARTESAN\%C3\%8DA-DELECUADOR.htm. Date accessed: 05/10/2016

[2] Quizhpe L. (2009), Revista Junta Nacional de Defensa del Artesano: Vol. 1, Página 5, Quito, Ecuador, Imprenta Latina.

[3] Licencia Creative Commons Atribución Compartir Igual 3.0, "ASP.NET”, [online], (2009, August 9), Available at: http://es.wikipedia.org/wiki/ASP.NET

[4] Taringa, "ExtJs," [online]. (2009, March, 4), Available at: http://www.taringa.net/posts/info/2112313/Coolite--Usa -ExtJs-con- Net__.html

[5] Licencia Creative Commons Atribución Compartir Igual 3.0, "Linq" [online]. (2011, May, 25), Available at: http://es.wikipedia.org/wiki/Language_Integrated_Query

[6] Available at: https://es.wikipedia.org/wiki/Firebug [7] ASP.net. "Creación de un Diseño Mediante Master Pages", 
[en línea]. (2009, April, 4),

[7] Enciso, L., Quezada, P., Fernandez, J., Figueroa, B., Espinoza, V.Analysis of performance of the routing protocols ad hoc using random waypoint mobility model applied to an urban environment (2016) WEBIST 2016 -

Proceedings of the 12th International Conference on Web Information Systems and Technologies, 1, pp. 208-213.

[8] Guay J. “Construyendo Reportes para Aplicaciones Web”, [online]. (2008, June 26) Available at: http://weblogs.asp.net/joseguay/archive/2008/06/26/

[9] Quezada Sarmiento, Pablo Alejandro. 2011. "Desarrollo del Portal Administrativo e Implementación de la Red de Datos para la Junta Provincial de Defensa del Artesano de Loja”. Ciencias Exactas y Tecnologías Aplicadas. UIDE. Loja. 188 p.

[10] Microsoft Corporation (2017). Available at: https://msdn.microsoft.com/es-es/library

[11] Newkirk J., Robert C. Martin, (2009), “La Programación Extrema en la Práctica”, Lima, Perú, Imprenta Editorial Macro.

[12] ASP.net. "Creación de un Diseño Mediante Master Pages", [online]. (2009, April, 4), Available at: http://www.esasp.net/tutoriales-asp-net/tutorial-61- 84/creacion-de-un-diseno-mediante-master-pages.aspx

[13] Enciso, L., Quezada, P., Barba-Guamán, L., Alarcón, P. “Open drugstores mobile app” (2016) Advances in Intelligent Systems and Computing, 444, pp. 797-806.

[14] Quezada, P., Enciso, L., Garbajosa, J. Using tools of cloud computing for defining, planning, monitoring innovation projects and knowledge generation [Uso de herramientas de computación en la nube para definir, planificar, controlar proyectos de innovación y generación de conocimiento](2015) XI Jornadas Iberoamericanas de Ingenieria de Software e Ingenieria del Conocimiento, JIISIC 2015, pp. 121-131.

[15] Licencia Creative Commons Atribución Compartir Igual 3.0, “Crystal Reports”, [online]. (2010, December 1), Available at: http://es.wikipedia.org/wiki/Crystal

[16] Quezada-Sarmiento P., Enciso L., Garbajosa J. "Use of body knowledge and cloud computing tools to develop software projects based in innovation", 2016 IEEE Global Engineering Education Conference (EDUCON), Abu Dhabi, 2016, pp. 267-272. doi: 10.1109/EDUCON.2016.7474564 Available at: http://ieeexplore.ieee.org/stamp/stamp.jsp?tp=\&arnumber $=7474564 \&$ isnumber $=7474513$

[17] C. Calderon-Cordova, C. Ramírez, V. Barros, P. A. Quezada-Sarmiento and L. Barba-Guamán, "EMG signal patterns recognition based on feedforward Artificial Neural Network applied to robotic prosthesis myoelectric control," 2016 Future Technologies Conference (FTC), San Francisco, CA, 2016, pp. 868-875.doi: 10.1109/FTC.2016.7821705

URL: http://ieeexplore.ieee.org/stamp/stamp.jsp?tp=\&arnumber=7821705\&isnumber=7821581

[18] P. A. Quezada-Sarmiento, L. E. Enciso-Quispe, J. Garbajosa and H. Washizaki, "Curricular design based in bodies of knowledge: Engineering education for the innovation and the industry," 2016 SAI Computing Conference (SAI), London, 2016, pp. 843-849.doi: 10.1109/SAI.2016.7556077

URL: http://ieeexplore.ieee.org/stamp/stamp.jsp?tp=\&arnumber=7556077\&isnumber=7555953

[19] P. A. Quezada-Sarmiento, M. M. Quezada, L. Pacheco-Jara and J. Garbajosa, "Evaluation of occupational and professional profiles in Ecuadorian context based on guide of Knowledge SWEBOK and ontological model," 2016 Third International Conference on eDemocracy \& eGovernment (ICEDEG), Sangolqui, 2016, pp. 42-47. doi: 10.1109/ICEDEG.2016.7461694

URL: http://ieeexplore.ieee.org/stamp/stamp.jsp?tp=\&arnumber=7461694\&isnumber=7461456

[20] Calderon-Cordova, C., Guajala-Michay, M., Barba-Guaman, R., Quezada-Sarmiento, P. Design of a machine vision applied to educational board game(2016) 2016 6th International Workshop on Computer Science and Engineering, WCSE 2016, pp. 808-811.

[21] Quezada P., Garbajosa J., Enciso L. (2016) Use of Standard and Model Based on BOK to Evaluate Professional and Occupational Profiles. In: Rocha Á., Correia A., Adeli H., Reis L., Mendonça Teixeira M. (eds) New Advances in Information Systems and Technologies. Advances in Intelligent Systems and Computing, vol 444. Springer, Cham

[22] Eras, A.G., Quezada, P.S., González, P.L., Gallardo, C. Comparing competences on academia and occupational contexts based on similarity measures (2015) WEBIST 2015 - 11th International Conference on Web Information Systems and Technologies, Proceedings, pp. 540-546. 